\title{
Leis da Interferência Cultural ${ }^{1}$
}

\author{
Itamar Even-Zohar \\ Tradução por Bárbara Andrade de Sousa*
}

Estamos em condições de formular leis gerais, ou, pelo menos, algumas demonstráveis regularidades, de interferência cultural? Milhares de trabalhos que tratam de um grande número de casos particulares de relações entre as sociedades e as culturas foram produzidos, mas existem muito poucos esforços para generalizar com base neste vasto conhecimento acumulado. Este artigo é um desses esforços, basicamente uma versão reformulada de tentativas anteriores, que o autor atual iniciou em 1978 (Even-Zohar 1978) para o domínio mais restrito da teoria literária e tem reescrito desde então. Como nas versões anteriores deste esboço, o que eu desejo alcançar não é uma lista definitiva de "leis", mas a própria possibilidade de formular e investigação de padrões repetitivos e regularidades.

\section{Contatos e Interferências}

Contatos podem ser definidos como uma relação entre as culturas, em que uma certa cultura A (a cultura fonte) pode tornar-se uma fonte de transferência direta ou indireta para outra cultura B (a cultura alvo). Uma vez que esta possibilidade é realizada, a interferência pode ser dita ocorrida. Interferência é, portanto, um procedimento que emerge no ambiente de contatos em que a transferência ocorreu.

Este tipo de relações tem sido sempre parte da existência histórica das sociedades humanas. E a maioria das sociedades humanas ao redor do mundo tem existido, sobrevivido e mudado graças à interferência. Sociedades isoladas, na medida em que tem existido - tem encontrado, por outro lado, muitas dificuldades, mesmo que tenham conseguido sobreviver (e muitas não conseguiram). Naturalmente, uma condição prévia para a interferência deve ser algum tipo de contato - direto ou indireto - mas o inverso não é necessariamente verdadeiro: o contato pode ocorrer sem gerar qualquer interferência substancial. Assim, "interferência" e "contatos" são processos distintos, definitivamente interligados, mas não totalmente sobrepostos. Eles podem ter histórias diferentes e em todo caso precisam ser tratados por diferentes conjuntos de questões.

Uma das manifestações de contatos é uma troca de bens. Se unilateral ou multilateralmente importados, esses bens podem vir a serem itens importantes na cultura da sociedade de importação. No entanto, somente se eles são convertidos em modelos generativos - ou seja, componentes ativos no repertório nacional - eles se tornam um caso claro de interferência. Assim, enquanto as sociedades humanas podem depender umas das outras para uma variedade de tarefas e objetivos, é apenas quando tais recursos são domesticados por uma cultura a ser produzidos localmente que estamos autorizados a falar de interferência. Naturalmente, as "fronteiras" entre os casos de contato ativo (ou seja, uma forte presença de produtos importados) e interferências não são claras. No entanto, o princípio básico aqui é a separação do item transferido a partir da fonte de exportação e sua independência que se seguiu: uma vez que a fonte é necessária para a fabricação do item de repertório em questão, justifica-se a considerar o caso como interferência. Uma vez que a interferência ocorreu, a questão de fonte/origem não é mais relevante. Para a maioria dos membros de uma comunidade, uma vez introduzidos no seu repertório, o destino de um item em termos de sucesso ou fracasso se torna um assunto interno. 
Diferentes tipos de contatos podem criar diferentes tipos de interferência, dependendo principalmente se os contatos são diretos ou indiretos. No caso de contatos diretos, uma cultura fonte está disponível para ser acessada por membros da cultura alvo sem intermediários institucionalizados. Por exemplo, no caso de grupos minoritários que vivem fisicamente entre grupos maioritários, sendo expostos diariamente à cultura da maioria, a interferência pode ser muito mais potente do que nos casos em que o alvo pode em certa medida evitar a fonte. Por outro lado, no segundo tipo, os contatos são intermediados através de agências, tais como vários tipos de importadores. Embora em ambos os casos a importação possa ser um importante canal para a transferência real, é evidente que, quando intermediários são indispensáveis, seu papel como procedimento institucionalizado distinto é mais indispensável. Nesses casos, muitas vezes, lidamos frequentemente com um pequeno grupo de agentes que operam como empresários em e para uma cultura alvo. Claramente, a exposição maciça pode apoiar significativamente o impacto de interferência. Mas tal exposição por si só não é nem suficiente nem uma condição necessária para que a interferência ocorra.

Condicionados por nossa tradição moderna, tendemos a pensar sobre as sociedades envolvidas nos contatos e interferências como entidades bem demarcadas, principalmente distintas étnica ou nacionalmente, de posse de repertórios culturais bem definidos. Isto é, no entanto, uma visão do assunto indevidamente limitada. A interferência funciona para todos os tamanhos e níveis de configurações sociais: famílias, clãs, tribos, "classes", grupos étnicos, grupos organizados geograficamente, bem como nações ou grupos de nações. Assim, não há necessidade de fazer uma distinção teórica entre os chamados contatos intrassistêmicos e intersistêmicos, e interferências, embora, na prática, possa ser realizada através de diferentes procedimentos, ou opções bastante diferentes dentro dos mesmos procedimentos.

\section{Leis de Interferência}

Três grupos de aspectos podem provisoriamente ser distinguidos:

Princípios gerais de interferência.

1. A interferência é sempre iminente.

2. Interferência é principalmente unilateral.

3. A interferência pode ser restrita a certos domínios.

Condições para a emergência e ocorrência de interferência.

4. Contatos, mais cedo ou mais tarde geram interferência se não surgem condições de resistência.

5. Interferência ocorre quando um sistema precisa de itens indisponíveis dentro de seu próprio repertório.

6. A cultura torna-se uma fonte através de prestígio.

7. A cultura torna-se uma fonte através de domínio.

Processos e procedimentos de interferência.

8. A interferência pode ocorrer em apenas uma parte da cultura alvo; ela pode então proceder a outras partes.

9. Um repertório apropriado não necessariamente mantém funções da cultura fonte.

1. Princípios gerais de interferência.

No. 1. A interferência é sempre iminente.

A onipresença de interferência nem sempre é óbvia. Uma vez que os canais de transferência real podem estar na periferia, e, portanto, não "visíveis" (a partir do ponto de vista da cultura oficial), e uma vez que é muitas vezes o caso em que somos confrontados com os resultados posteriores, domesticados de interferência em vez das fases iniciais, 
parece "natural" não hipotetizar a interferência como primeira opção para casos indicados. No entanto, pesquisas demonstraram que, provavelmente, todos os sistemas conhecidos por nós surgiram e se desenvolveram com a interferência, desempenhando um papel proeminente. Não há uma única cultura que não surgiu através da interferência com uma cultura mais estabelecida; e nenhuma cultura pode se manter sem interferência em um momento ou outro durante a sua história. Foi provado que a interferência é a regra e não a exceção, independentemente se é uma ocorrência maior ou menor para uma determinada cultura. É somente quando os processos de interferência invisíveis são descobertos que a sua esmagadora presença pode ser plenamente reconhecida e estimada.

Uma implicação desse reconhecimento é que, quando se deve optar por um caso entre a hipótese de desenvolvimento separado contra a hipótese de interferência, a não ser refutável por razões muito claras, apesar de nossas inclinações aceitas, a prioridade deve ser dada à hipótese de interferência. O significado disso é que um pesquisador é assim encorajado a procurar interferência como uma opção altamente provável, e rejeitá-la somente se uma solução, não-interferência, possa se mostrar mais forte.

É verdade que não temos evidência de interferência para algumas culturas que atualmente parecem remotas e isoladas. Mas tendo em conta a evidência esmagadora de interferência para a maioria das culturas do mundo, a falta de provas em casos especiais pode sugerir que a prova ainda não está acessível ao invés de não terem havido interferências. O que parecia, apenas um século atrás, serem civilizações díspares, agora têm sido mostradas como tendo sido interligadas e conectadas. Tais casos, como a nãoinvenção da roda pelos incas, certamente reforçam a hipótese da falta de contatos, mas por outro lado, também demonstram o papel central que a interferência deve ter desempenhado na difusão de tais invenções.

O fato de que nós não sabemos o momento como a Suméria - cultura mais antiga conhecido no mundo - surgiu, não prova a não-interferência. Alguns estudiosos apontaram evidências que sugerem que alguma civilização mais antiga estava ao fundo da Suméria. Mas, mesmo supondo que aceitar Suméria como progenitora da cultura mundial (o que significa que estamos dispostos a tomá-la como uma cultura sem interferência), para quase todas as outras culturas há provas abundantes de interferência. Além disso, a maioria destas culturas pode-se demonstrar descendente ou da mesma linhagem sumeriana. Não há nenhuma dúvida sobre a Acadiana (assíria-babilônica), sendo a primeira e mais conspícua herdeira da Suméria. Com efeito, os processos que podem ser reconstruídos para o caso sumério-acadiano são notavelmente semelhantes a muitos outros casos que ocorreram em várias culturas no decurso da história mais tarde.

As características proeminentes neste caso são (1) uma adoção do sistema sumério de escrita; (2) a adoção parcial da língua suméria pelos acádios, a ser mantida por um longo tempo, lado a lado com o acadiano como uma linguagem altamente reverenciada; (3) traduções interlineares (em acadiano), nos principais textos sumérios emprestados pelos acádios; (4) traduções regulares; (5) adaptações e elaborações de textos sumérios; e (6) novos textos com base no novo repertório que surgiu e se desenvolveu em acadiano através da interferência suméria.

O resto das culturas do Crescente Fértil definitivamente devem seu repertório, bem como outros componentes do seu sistema de cultura, à cultura acadiana. Para cada uma das culturas escritas em Ugarítico (? -1200) e hitita (1650-1200 a.C.), não só afinidades no repertório podem ser demonstradas, mas também muita evidência direta e indireta sobre as possíveis condições que devem ter gerado a interferência entre elas. A antiga cultura hebraica, disponível para nós através dos livros do Antigo Testamento (o qual, embora certamente apenas uma parte do que foi produzido nesta cultura, ainda é muito mais do que 
resta para nós a partir de Fenícia), é passível de ligação não só com a acadiana (e suméria via acadiana), mas evidentemente também para ugarítico (como foi demonstrado por Ginsberg [1936, 1946], Cassuto [1958, 1972], Gordon [1977], Caquot et al. [1974]; ver também Avishur 1979).

De ugarítico, fenícia, e hitita o caminho vai para a Grécia. Lá, há controvérsia sobre a origem fenícia do alfabeto grego, e há grande acordo sobre a origem do Oriente Médio de alguns das principais características da mitologia grega. Que nenhuma evidência clara sobre o caso homérico pode ser fornecida não é de se admirar. Os textos homéricos são obviamente produzidos por um repertório nacional já avançado. Embora ele possa lembrarnos de seus precedentes externos (possivelmente através da intermediação de renderizações hititas dos textos clássicos da Mesopotâmia, pelo menos tanto quanto os contatos com os antigos Ionians e Achaeans) que, obviamente, também tem suas próprias particularidades que não podem ser rastreadas até qualquer fonte externa.

No. 2. Interferência é principalmente unilateral.

Não existe simetria nos contatos culturais. Uma cultura alvo é, com mais frequência, interferida por uma cultura fonte a qual pode ignorá-la. Existem, também, casos em que pode haver alguma pequena interferência em uma direção e uma grande em outra.

No. 3. Interferência normalmente não acontece em todos os níveis de cultura.

No caso de duas comunidades geograficamente contíguas ou mistas, ou de outra maneira ligadas ("ligações geográficas" podem ser rotas comerciais, bem como alguma consciência estabelecida da "existência da outra"), interferência pode ocorrer em vários níveis, mas não necessariamente em todos os níveis de cultura. No entanto, parece difícil fornecer evidência para casos quando a interferência seria restrita a apenas um setor da cultura, enquanto todos os outros setores permanecem intactos. Ao mesmo tempo, com comunidades geograficamente separadas uma da outra, a interferência parcial é completamente concebível.

É precisamente por causa da estrutura sistêmica heterogênea da cultura que uma cultura alvo pode ter contato e transferir a partir de apenas algumas seções de uma cultura fonte. Uma cultura-alvo nunca é exposta à totalidade de alguma fonte, mesmo quando geograficamente próxima a ela ou misturada a ela. Os estudos sobre imigração, aculturação e assimilação fornecem ampla evidência de apoio a este.

2. As condições de emergência e ocorrência de Interferência

No. 4. Contatos, mais cedo ou mais tarde geram interferência se não surgem condições de resistência.

Os contatos entre as comunidades não necessariamente geram interferência. Comunidades podem trocar qualquer tipo de bens, de informações, apoio político, ou turismo sem posteriormente serem afetadas. Espalhar informações recebidas a partir da fonte, se familiarizar com a estrutura política da fonte, a fim de ser capaz de lidar com ela (tal como é frequentemente o caso das nações menores vs. maiores), e trazer lembranças de uma viagem não necessariamente geram interferência. Além disso, as comunidades podem viver lado a lado, mesmo misturadas uma com a outra, aparentemente sem interferência. ${ }^{2}$

Não é uma tarefa fácil, no entanto, determinar em que ponto concordaríamos que a interferência começou a ter lugar. Contatos duráveis, enquanto não produzem interferência visivelmente visível, podem, no entanto, gerar condições de disponibilidade, o que facilitará a interferência. Certas atitudes amplamente aceitas em direção a contatos prováveis, e, posteriormente, interferência, podem afetar o comportamento real quando a interferência se torna iminente. Às vezes, sociedades altamente nacionalistas rejeitam qualquer interferência, porque ela é sentida como uma ameaça à integridade nacional. Em 
outras ocasiões, o desejo de mudança pode promover uma atitude favorável em relação a ocorrências em uma outra sociedade, e com a ajuda desta, em caso de transferência, se pode esperar estar longe de uma situação indesejada.

No último terço do século XIX, quando Paris tinha se tornado um centro internacional, vários intelectuais franceses (ou talvez "fazedores da opinião pública") tanto perpetuaram quanto reforçaram atitudes xenófobas. Por exemplo, Zola, Daudet e os Goncourt (para citar apenas alguns) se opuseram violentamente à introdução de quaisquer produtos de alta cultura do exterior, tentando demonstrar a incompatibilidade da cultura estrangeira com "o espírito francês". Zola, de quem normalmente se lembra como defensor da justiça humanista, combinada com seu credo literário sua atitude desfavorável aos estrangeiros ao criticar escritores franceses que localizam o seu cenário em algum lugar não-francês. ${ }^{3}$

Por outro lado, outras comunidades não se ressentem tão violentamente emprestando de outras culturas, e pode-se observar algum tipo de abertura cultural a outras culturas (e a multiplicidade das culturas em geral). Em outras sociedades, "qualquer coisa que vem do exterior deve ser boa", então dizer que "isto já existe no exterior, por que estamos atrasados" é bem aceito. Com contatos mais próximos e mais íntimos entre as comunidades, como aqueles entre as populações polonesas e as ucranianas no Império Austro-húngaro Oriental, questiona-se se as ideologias nacionais separatistas não nos cegaram para a interferência que de fato ocorreu. No entanto, a difícil questão aqui é saber se nos justificamos ao concluir que os contatos mais cedo ou mais tarde (e se desejarem ou não) irá gerar, provavelmente, algum tipo de interferência. Se argumentar que tal interferência poderia ter ocorrido por causa de algum tipo de vácuo, indiferença, ou falta de resistência no alvo - isso equivaleria a mesma hipótese.

Consequentemente, embora uma comunidade possa resistir a interferência, mesmo em casos de contatos inevitáveis, ela não pode resistir em todos os níveis de interferência ou por um longo período de tempo. Portanto, a questão evidente é quando a interferência se torna um fator importante na cultura, e não se a interferência opera em uma cultura ou não, i.e., no caso de contatos. À luz de nossa compreensão da estratificação, seria bastante plausível supor, por exemplo, uma interferência durável na periferia da cultura. Isso pode ser incubado por um bom tempo, mesmo por várias gerações, antes de surgir, por assim dizer, na esfera da cultura oficial ou dominante. Mas ele emerge ou deixa de estar sujeito às condições predominantes no centro, o que pode encorajar a interferência ou neutralizar a resistência a ele.

Se esperamos que os contatos gerem interferência sob quaisquer condições, provavelmente ficaremos intrigados com casos que parecem "anômalos". Por exemplo, nos perguntamos como é que, depois de tantos anos de coexistência, vários grupos étnicos ou nacionais em um território relativamente pequeno como a Europa ainda se mantêm distantes, apesar de uma herança cultural comum e contatos intensivos (bem como interferências em vários níveis). Somente a Suíça poderia ser motivo de perplexidade, mas mesmo a França - o estado mais centralizado e aparentemente homogeneizado da Europa ainda tem minorias pequenas e grandes que resistiram à interferência em diversos níveis culturais, como os bretões e, até certo ponto, os occitanos (mais de 16 milhões de pessoas).

Aqui estão algumas breves observações sobre vários casos:

(1) A cultura judaica $x$ helenística-romana na Palestina 100 a.C.-600 d.C. Levou cerce de 200 a 400 anos para que certas características da cultura helenística fossem aceitas pelos judeus depois de ter resistido fortemente. Só depois de se tornarem itens neutralizados que eles não poderiam mais representar uma ameaça possível à cultura local. $^{4}$ 
(2) culturas hebraicas vs. árabes na Mesopotâmia após a conquista muçulmana daquele território no século VII. A nova língua foi rapidamente adotada pela população local, embora não eliminando completamente a língua vernacular do grupo. ${ }^{5}$ Mas foram necessários quase trezentos anos para que a cultura judaica utilizasse a cultura árabe, adjacente e superior, em seus modos culturais centrais de produção (Drory 1988, 2000).

No. 5. A interferência ocorre quando um sistema precisa de itens indisponíveis dentro de seu próprio repertório.

Uma "necessidade" pode surgir quando uma nova geração sente que as normas que governam o sistema não são mais eficazes e, portanto, devem ser substituídas. Se o repertório doméstico não oferece nenhuma opção nesse sentido, enquanto um sistema adjacente acessível parece possuí-las, a interferência provavelmente ocorrerá.

Pode-se perguntar se tal "necessidade" pode de fato surgir não como consequência de algum desenvolvimento interno em uma cultura, mas como resultado da existência de certas opções em uma cultura acessível adjacente. Isso deve permanecer uma questão aberta nesse estágio.

No. 6. A cultura torna-se uma fonte através de prestígio.

Uma cultura pode se torna uma fonte, porque é considerada um modelo de imitação. Vários fatores contribuem para tornar-se uma cultura de prestígio. $\mathrm{O}$ estabelecimento e a presença altamente visível em uma rede mundial, que cria um alto grau de interconectividade, estão entre os fatores de prestígio. O poder político e/ou econômico não são condições necessárias para adquirir prestígio per se, mas são certamente indispensáveis para criar alta visibilidade/presença que, por sua vez, criam prestígio. Além disso, uma posição de poder político, que ajudou numa fase inicial a criar visibilidade/presença, não será mais necessária após o prestígio ter sido alcançado. Assim, um poder politicamente superior pode emprestar maciçamente para setores da cultura que não foram criados ou promovidos domesticamente a partir de um poder politicamente inferior que estabeleceu prestígio cultural para esses setores. Este é claramente o caso da cultura grega em Roma.

Tomando outro caso, o da cultura francesa, não é de todo claro se devemos atribuir seu prestígio, por vários séculos entre as culturas europeias, ao poder político da França. Embora isso possa ser verdade por alguns períodos, não é totalmente assim para outros. A difusão de modelos e produtos culturais franceses (materiais e semióticos) durante a Alta Idade Média (1000-1400) não pode ser separada da centralidade da França devido a sua posição no Império Carolíngio; no entanto, só mais tarde a França alcançou sua posição de poder e pôde exercer políticas de poder com repercussões no nível do consumo cultural. Acredito que temos que reconhecer que seu prestígio foi estabelecido - em premissas culturais - muito antes de seus dias de grande poder, e persistiu muito depois que esse poder declinou. ${ }^{6}$

O que a França poderia oferecer desde um estágio relativamente inicial era o estabelecimento. Ela já havia desenvolvido muitas instituições acessíveis em uma grande variedade de níveis, quando outras culturas começaram a se organizar. Como a Inglaterra e antes, a Irlanda, ela poderia oferecer, por exemplo, vários tipos de especializações (linguística, teológica, artesanal) que estavam envolvidas com a religião recém-aceita em vastos territórios da Europa, que não faziam parte do Império Romano. Nos termos de Bourdieu, seria apropriado reconhecer que, além de suas riquezas mundanas (que tão fortemente haviam tentado a periferia durante os séculos IX e X), a França acumulara um imenso capital cultural que nenhuma entidade, que desejasse organizar-se ao longo do mundo a rede de competição e paridade, poderia se dar ao luxo de ignorar. É por isso que 
vemos a cultura francesa desempenhar um papel nas sociedades nórdicas, ou na Alemanha e na Rússia em vários pontos de sua história.

Embora o modelo do cristianismo adotado na Islândia e na Noruega derivasse principalmente da Inglaterra, a cultura francesa desempenhou um papel importante para ambos. Parece que a França sediou um dos pais fundadores da cultura islandesa Sæmundr o culto (1056-1133) - legitimando assim mais contatos e criando consciência da cultura francesa como fonte e recurso permanentemente disponível para várias medidas centrais tomadas pela igreja islandesa. (Para fontes e mais detalhes ver Gelsinger 1981: 135-140). Parece também que a França poderia ter fornecido especialistas que eram necessários para ensinar na recém-criada Escola do Norte de Hólar certas habilidades importantes da cultura europeia (ver Turville-Petre 1975: 111). ${ }^{7}$ Além disso, os artefatos religiosos franceses, especialmente os de Dinant, Limoges e Rheims, foram importados para a Islândia e tiveram grande impacto na arte local(Björnsson 1975: 270). Não há provas, no entanto, de que estas foram trazidas diretamente da França. (Gelsinger, por exemplo, favorece fortemente a ideia de que, em vez de estabelecer laços diretos, os noruegueses atuaram como intermediários entre a Islândia e a França).

Assim, a posição da França na alta cultura oficial nórdica (particularmente norueguesa-islandesa) havia sido estabelecida muito antes de começar a desempenhar um papel mais decisivo para outras seções dessa cultura. Pois, com as fontes exegéticas franco-latinas, também surgiu uma quantidade abundante de imagens de cavalaria francesa que criaram um repertório completo de novas atitudes. Na criação local de textos escritos uma atividade altamente central para a cristalização das sociedades nórdicas no novo mundo da Idade Média -, esta imagem foi principalmente transferida via tradução, mas logo foi apropriada para a produção de textos locais. Em um número notável de sagas islandesas posteriores, o modelo de cavalaria do mundo, que se acredita ter penetrado no amplo campo das atitudes populares (Sveinsson 1953) torna-se muito conspícuo. (Hallberg 1962; Turville-Petre 1975: 82 [e referências ali]; Gelsinger 1981; Lönnroth 1965, 1976; também Stefánsson 1975). ${ }^{8}$

No. 7. A cultura torna-se uma fonte através de domínio.

Uma cultura pode ser selecionada como uma cultura fonte quando é dominante devido a condições extra culturais. Naturalmente, uma cultura dominante muitas vezes tem prestígio, mas a posição dominante não resulta necessariamente desse prestígio. Um caso atual nesta categoria é uma cultura "inevitável" por uma potência colonial, que impõe sua linguagem e textos a uma comunidade subjugada. Por exemplo, o fato de que o inglês e o francês dominaram muitas culturas sob sua influência política é simplesmente devido a essa influência. $\mathrm{O}$ mesmo parece ser verdade basicamente para a maioria dos casos de grupos minoritários.

As potências coloniais ou imperialistas nem sempre parecem ter o mesmo interesse em inculcar suas culturas no povo subjugado, mas os resultados podem eventualmente ser quase os mesmos. Os respectivos comportamentos da França e da Inglaterra vis-à-vis essa questão foram diferentes. No entanto, o inglês conseguiu criar raízes em países como a Índia, o Iraque, ou a África negra, quase tão plenamente quanto o francês no norte da África, Líbano e Indochina.

O domínio do poder do tipo imperialista, portanto, força os contatos em um sistema e, portanto, pode gerar interferência apesar da resistência do sistema. No entanto, nos casos em que o sistema de destino ainda não está estabelecido - ou em crise - pode não desenvolver nenhum mecanismo de rejeição. Tal mecanismo pode, no entanto, evoluir em um estágio posterior, quando muitos repertórios supostamente apropriados se mostraram meramente temporários. 


\section{Processos e Procedimentos de Interferência.}

No. 8. Os contatos podem ocorrer em apenas uma parte da cultura alvo; ela pode então proceder a outras partes.

Mesmo quando as apropriações são "pesadas", não há necessariamente uma interferência geral. Geralmente, certas seções permanecem intocadas, enquanto outras passam por uma invasão maciça, ou são literalmente criadas por apropriações. Por exemplo, um modelo que não existia em uma cultura alvo pode ser inserido e incorporado a ele por meio de apropriação.

Similarmente, a interferência pode ser confinada a apenas um estrato, por exemplo, ao centro ou à periferia da cultura alvo. Um repertório de cultura fonte pode, assim, primeiro interferir com uma camada inferior ou superior de uma cultura alvo e depois passar para outras camadas. Embora inicialmente gerado por interferência, quando esse repertório "aprofunda", ele não é mais uma questão de interferência direta, mas já é um processo interno dentro da cultura alvo. Como nos estudos culturais tradicionais a interferência - entendida em termos de "influência" - é considerada uma questão de superioridade versus inferioridade, não é provável que seja aceito que a parte "influenciadora" pode ser de natureza menos "sofisticada" do que o "influenciado".

Muitas culturas periféricas se apropriam de características do repertório cultural comumente aceito depois que elas estão bem estabelecidas nas culturas centrais de uma época. Isso não é necessariamente realizado por apropriação de uma fonte importante, mas muitas vezes ocorre através de intermediários secundários, que elaboraram modelos mais esquematizados e possivelmente digeríveis em termos de apropriabilidade.

No. 9. Um repertório apropriado não necessariamente mantém funções da cultura fonte.

A hipótese sobre a regularidade da mutação de uma função transferida de sua posição original dentro de um sistema, como pode ser formulada com base na obra de Tynjanov (especialmente Tynjanov 1929), é suficientemente apoiada por estudos de interferência. Qualquer item apropriado de uma fonte pode assumir, em vista da superioridade das restrições domésticas, uma função diferente dentro do alvo.

Se tomado dentro de uma estrutura maior, qualquer cultura - que pode ter evoluído como um polissistema completo ou parcial - pode adquirir certos itens de repertório (ou outros elementos do sistema) por muito tempo depois de eles terem conseguido institucionalizar-se no sistema em primeira instância. Desse ponto de vista, os produtos gerados em qualquer cultura alvo em uma etapa posterior a sua primeira instância são, com toda a probabilidade, de natureza secundária quando comparados com os primários do sistema iniciador. Isso, no entanto, também não tem importância, pois o que conta é a posição assumida por esses itens dentro do alvo, não seus itens comparáveis dentro de qualquer fonte. É somente quando ocorre uma situação de reciprocidade, até mesmo uma menor (por exemplo, através de traduções periféricas) que tais questões se revelam. Esta é uma evidência definitiva do valor dependente do sistema de qualquer item dentro de uma determinada cultura.

Isso implica que uma cultura alvo frequentemente ignora os elementos contemporâneos de uma cultura fonte, e remonta a uma fase diacrônica anterior, muitas vezes ultrapassada do ponto de vista do centro da cultura fonte. Mas enquanto em certos casos a direção da interferência pode ser uma única linha homogênea, em outras instâncias várias tentativas concorrentes e não congruentes podem ser realizadas por diferentes grupos dentro da cultura alvo. As características contemporâneas podem, assim, ser misturadas com as das fases anteriores. Isto implica, claramente, que a posição sistêmica de itens específicos na fonte não é necessariamente consequência da alvo. Essa posição na 
origem não deve ser tomada como garantida quando o problema do possível status do item no destino é discutido. Se, em um caso específico, essa posição for relevante, essa relevância deve ser fortemente apoiada por evidências defensáveis.

$\mathrm{Na}$ presente etapa da teoria da interferência, não parece possível concluir sob quais condições uma cultura alvo tenderia a usar um repertório ultrapassado ou novo na fonte. Os membros de um grupo minoritário, muitas vezes distante dos centros de inovação (geralmente cidades capitais), adquirem seu conhecimento de uma cultura fonte de uma maneira mais tradicional do que seus contemporâneos mais centralmente situados. Mas o oposto pode ser, às vezes, também a verdade. Por conseguinte, não se justifica generalizar com base em casos restritos. Pelo menos devemos admitir que muita pesquisa ainda precisa ser realizada, em uma escala suficientemente grande, em um grande número de culturas, para nos permitir solidificar nossas generalizações temporárias.

\section{Laws of Cultural Interference}

This is a rewriting of my paper "Laws of Literary Interference," Poetics Today 11:1, pp 53-72 (based in its turn on Even-Zohar 1978), adapted to the field of culture research. This conversion has been relatively unproblematic, because the proposals in the original paper actually transcended from the outset the restricted field of "literature" and were almost integrally applicable to the larger field of culture. I am grateful to Gideon Toury for his critical reading and invaluable suggestions.

\footnotetext{
${ }^{1}$ Esta é uma reescrita do meu artigo "Leis de Interferência Literária," Poética Hoje 11: 1, pp 53-72 (baseado por sua vez em Even-Zohar 1978), adaptado para o campo da cultura investigação. Esta conversão tem se dado relativamente sem problemas, porque as propostas no artigo original realmente transcenderam desde o início o campo restrito de "literatura" e foram quase integralmente aplicáveis ao maior domínio da cultura. Sou grato a Gideon Toury por sua leitura crítica e sugestões inestimáveis.

* Graduada em Letras - Inglês e respectivas literaturas pela Universidade Federal de Juiz de Fora (2013), Bacharelado em Tradução - Inglês/ Português pela Universidade Federal de Juiz de Fora (2016) e Letras Português e respectivas literaturas pela Universidade Federal de Juiz de Fora (2014). Atualmente cursa Especialização em Tradução de Inglês pela Estácio de Sá. A revisão da tradução foi feita pela aluna Isabella Aparecida Nogueira Leite, da mesma instituição.

2 A própria integração de bens de qualquer natureza em um sistema alvo faz claramente uma ocorrência de interferência, embora não produzida localmente. Se os americanos comprarem camisas feitas em Hong Kong, isso não faz a cultura de Hong Kong interferir na cultura americana. Mas supondo que as camisas de Hong Kong são diferentes das americanas, e primeiramente não aceitas imediatamente, mas sim gradualmente, ainda são plenamente adotadas pelos americanos. Apesar de não envolverem alterações no repertório de fábricas de camisas americanas, o repertório americano teria realmente mudado por essa adoção. Claro que, se os americanos passarem para produção de camisas a forma de Hong Kong, não há dúvida de que a interferência inequívoca de fato teria ocorrido.

${ }^{3}$ Em uma revisão de uma peça de Ernst Blum, Zola diz: "Aussi, quelle étrange idée, d'être allé choisir la Suède, qui compte si peu dans les sympathies populaires de notre pays. Ce choix malheureux suffit à reculer l'action dans le brouillard. On raconte que M. Ernst Blum a promené son drame de nationalités en nationalités, avant de le planter à Stockholm. Il a eu ses raisons sans doute; mais je lui prédis qu'il s'en repentira pas moins d'avoir poussé le dédain de nos préoccupations quotidiennes jusqu'à nous mener dans une contrée dont la grande majorité des spectateurs ne sauraient indiquer la position exacte sur la carte de l'Europe. Nous rions et nous pleurons où est notre coeur" (Zola 1928: 187). Veja também Ahlström 1956: 164-165 e Nyholm 1957/59.

${ }^{4}$ Estes envolviam uma variedade de culturas, não apenas em arquitetura e vestuário, mas também padrões e linguagem de enterro. A descoberta da arte pictórica helenística em várias sinagogas, na Galileia e na Síria (a mais famosa em Dura-Europo), foi uma verdadeira surpresa para os historiadores. (Para mais considerações ver Kraeling 1956.) A absorção gradual de componentes gregos na língua aramaica dos tempos romano e bizantino na Palestina é um fenômeno reconhecido. No entanto, é surpreendente descobrir, mais tarde no aramaico judeu palestino, palavras-chave na vida da comunidade palestina judaica como "kyrios" (Deus) e "angelos" (anjo)! (Ver Heineman 1973.) Para uma discussão de itens arquitetônicos como culturas ver Tsafrir 1981, 1984.
} 


\begin{abstract}
${ }^{5} \mathrm{Na}$ verdade, os judeus (assim como os cristãos) da Mesopotâmia (Iraque) adotaram uma variedade linguística que mais tarde desapareceu na sociedade muçulmana, ao mesmo tempo em que a fundia com seu vernáculo aramaico anterior para criar seus respectivos vernáculos particulares. (Ver Blanc 1964 a Blau 1965, 1967, a 1988 para o árabe judaico e cristão).

${ }^{6} \mathrm{O}$ papel de uma poderosa visão de mundo organizadora, como a religião, ao fazer com que a interferência funcione por meio do prestígio, é evidente em todos os tipos de ideologias. Não há diferença a este respeito entre o papel que o cristianismo desempenhou na Alta Idade Média e o papel desempenhado pelas ideologias posteriores, como a Revolução Francesa e mais recentemente a Revolução Russa.

${ }^{7}$ A escola de Hólar foi fundada em 1106, quando Jón Ögmundarsson, recém consagrado bispo em Lund, retornou à Islândia. "Entre os professores que Jón empregou estava Gísli Finsson, de Gautaland (Suécia), que era diretor e ensinava latim. Outro professor chamado Ríkini, e ele era descrito como francês. Ele ensinava canto e criação de versos, e era ele mesmo hábil em ambos" (Turville-Petre 1975: 111). In Jóns saga helga (A vida de São João), escrito durante os primeiros anos do século XIII pelo monge Gunnlaugr Leifsson (falecido em 1218), um longo parágrafo é dedicado a Ríkini. Esta saga foi originalmente escrita em latim e depois traduzida pelo autor para o islandês, o único texto sobrevivente. Embora escrito no estilo normal de estoque da hagiografia europeia padrão (Boyer 1986: 63), a descrição amada de Ríkini testemunha, pelo menos em parte, e indiretamente, a alta apreciação de suas habilidades excepcionais. Embora, seu colega estrangeiro da Suécia foi nomeado diretor, cantor e versador, parece ter dado mais importância aos alunos do que ao latim ("Grammatica"), e Ríkini provavelmente gostava das pessoas e era querido por elas (Jóns saga helga [eldri gerð], 1953, etc.: 42). É claro que a presença de Ríkini não é, por si só, evidência de qualquer transferência maciça de cultura francesa para a Islândia, mas, juntamente com outros fatores de interferência, diretos e indiretos, é definitivamente um sinal de uma consciência da cultura francesa na época.

${ }^{8}$ A perpetuação do poder cultural, apesar do declínio político, é bem atestada. Os povos conquistados muitas vezes transmitiram sua cultura a seus conquistadores em virtude desse prestígio irremovível. Assim, as tribos germânicas conquistadoras adotaram os componentes mais fundamentais de sua cultura oficial dos povos gaélicos e itálicos conquistados. Os colonizadores também podem se comportar como tais conquistadores, como é provavelmente o caso dos acádios, que adotaram a cultura dos sumérios e valorizaram a língua e a herança dos antigos durante séculos. A cultura helenística foi respeitosamente tratada pelos romanos e pelas culturas romanas da Itália e da Gália por seus respectivos invasores germânicos.
\end{abstract}

\title{
REFERÊNCIAS
}

Ahlström, Stellan 1956. Strindbergs erövring av Paris Almqvist and Wiksell).

Björnsson, Björn Th. 1975. "Myndlistarsaga," in Saga Islands, II, edited by Sigurður Líndal, 261281 (Reykjavík: Hið íslenzka bókmenntafélag, Sögufélagið).

Blanc, Haim 1964. Communal Dialects in Baghdad (Cambridge: Harvard University Press).

Blau, Joshua 1965. The Emergence and Linguistic Background of Judaeo-Arabic (Oxford: Oxford University Press).

Blau, Joshua 1967. A Grammar of Christian Arabic, I-III (Louvain: Secrétariat du corpus sco).

Blau, Joshua 1988. Studies in Middle Arabic and Its Judaeo-Arabic Variety (Jerusalem: Magnes Press).

Even-Zohar, Itamar 1990. "Laws of Literary Interference." Polysystem Studies [=Poetics Today 11:1 (1990)], pp. 53-72.

Gelsinger, Bruce E. 1981. Icelandic Enterprise: Commerce and Economy in the Middle Ages (Columbia: University of South Carolina Press)

Hallberg, Peter 1962. The Icelandic Saga, translated, with introduction and notes, by Paul Schach (Lincoln: University of Nebraska Press). 
Heinemann, Joseph 1973. "Remnants of Ancient Piyyutim in the Palestinian Targum Tradition," Ha-Sifrut 4(2), pp. 362-375 [in Hebrew; English summary: viii-xix].

Lönnroth, Lars 1965. European Sources of Icelandic Saga-Writing (Stockholm).

Lönnroth, Lars 1976. Njál's Saga: A Critical Introduction (Berkeley and Los Angeles: University of California Press).

Needham, Joseph 1981. Science in Traditional China: A Comparative Perspective (Cambridge: Harvard University Press; and Hong Kong: Chinese University Press).

Nyholm, Kela 1957-1959. “Henrik Ibsen paa den franske Scene,” in Ibsenårbok 1957-59, pp. 7-78.

Pallottino, Massimo 1981. Genti e culture dell'Italia preromana (Rome: Jouvence).

Stefánsson, Magnús 1975. "Kirkjuvald Eflist," in Saga Islands, II, edited by Sigurður Líndal, pp. 57-144 (Reykjavík: Hið íslenzka bókmenntafélag, Sögufélagið).

Sveinsson, Einar Ólafur 1953. The Age of the Sturlungs. Ithaca: Cornell University Press.

Turville-Petre, Gabriel 1975 [1953]. Origins of Icelandic Literature (Oxford: Clarendon Press).

Tynjanov, Jurij 1929. Arxaisty i novatory (Moscow: Akademia) [rpt.

Munich: Fink, 1967]. 